\title{
Urban -Rural Differential in the Association Between Household Wealth Index and Anemia Among Women in Reproductive Age in Ethiopia, 2016.
}

\author{
Sefealem Assefa \\ Bahir Dar University \\ Dessalegn Demeke \\ Bahir Dar University \\ Mekuriaw Mesfine \\ Bahir Dar University \\ Biruk Getahun \\ Bahir Dar University \\ Adela Alemu \\ Bahir Dar University \\ Yirga Mengiste \\ Bahir Dar University \\ Getasew Aknaw \\ Bahir Dar University \\ Dagninet Abie \\ Bahir Dar University \\ Teshager Abate ( $\nabla$ teshagerhylemarriam@gmail.com ) \\ Bahir Dar University
}

\section{Research Article}

Keywords: Anemia, Women, Reproductive age, Factors, Urban, Rural

Posted Date: November 30th, 2020

DOI: https://doi.org/10.21203/rs.3.rs-110045/v1

License: (c) (i) This work is licensed under a Creative Commons Attribution 4.0 International License.

Read Full License 


\section{Urban -rural differential in the association between household wealth index and anemia among women in reproductive age in Ethiopia, 2016.}

\section{Teshager Weldegiorgis Abate', Biruk Getahun², Mekuriaw Mesfin Birhan², Getasew Mulatu}

Aknaw $^{3}$, Sefealem Assefa Belay ${ }^{4}$, Dessalegn Demeke ${ }^{2}$, Dagninet Derebe Abie ${ }^{5}$, Adela Memberu Alemu $^{6}$ and Yirga Mengiste ${ }^{6}$

${ }^{1}$ Department of adult health Nursing, School of Health Science, College of Medicine and Health Science, Bahir Dar University, P.O. Box 79, Bahir Dar, Ethiopia.

${ }^{2}$ Department of human physiology, School of medicine, College of Medicine and Health Science, Bahir Dar University, P.O. Box 79, Bahir Dar, Ethiopia.

${ }^{3}$ Department of emergency and critical care Nursing, School of Health Science, College of Medicine and Health Science, Bahir Dar University, P.O. Box 79, Bahir Dar, Ethiopia.

${ }^{4}$ Department of human biochemistry, School of medicine, College of Medicine and Health Science, Bahir Dar University, P.O. Box 79, Bahir Dar, Ethiopia.

${ }^{5}$ Department of pharmacy, School of Health Science, College of Medicine and Health Science, Bahir Dar University, P.O. Box 79, Bahir Dar, Ethiopia.

${ }^{6}$ Department of gynecology, School of medicine College of Medicine and Health Science, Bahir Dar University, P.O. Box 79, Bahir Dar, Ethiopia. 


\begin{abstract}
Background: Anemia is more prevalent among women, and it is a moderate public health problem in Ethiopia. The wealth status and place of residence of a woman have implications on the intervention of anemia. Studies that examined the relationship between women's wealth index status and place of residency in Ethiopia are scarce. We aimed to identify the urban-rural differential in the association between household wealth index and anemia among women of childbearing age in Ethiopia.

Method: A cross-sectional design was employed with nationally representative sample of 14100 women aged 15-49-year-old from the Ethiopian demographic and health survey conducted in 2016. Samples were selected by the two-stage clustering sampling method. The primary outcome was anemia in women of childbearing age. A hemoglobin level of below $11 \mathrm{~g} / \mathrm{dl}$ for pregnant women and $12 \mathrm{~g} / \mathrm{dl}$ for nonpregnant women was used as the indicator of anemia. Using a three-level random intercept model to explored associated factors at individual and household levels quantified the observed and unobserved variations between households' wealth index and place of residence.
\end{abstract}

Results: Women of low household wealth index category were anemic (29.6\%) than those middle and rich wealth index categories. Women who live in rural areas were $(25.5 \%)$ were anemic than those who live in urban. The odds of anemia were significantly higher in women of low household wealth category, compared to women of high household wealth category $(\mathrm{AOR}=1.37,95 \% \mathrm{CI}=1.14-1.65, \mathrm{P}<0.001)$. This is not true for women to live in urban residency.

Conclusion: Since the driver of anemia in this study is the palace of residency affecting women of reproductive age groups, novel public health interventions should consider urban residency those women with the lowest household wealth status.

Keywords: Anemia, Women, Reproductive age, Factors, Urban, Rural 


\section{Introduction}

Anemia is a health condition characterized by a low level of hemoglobin (HGB) in which blood has fewer red blood cells (RBC) than normal. A low HGB level impairs blood from delivering oxygen to the body tissues (1). Anemia is caused by a genetic defect, infections (malaria, hookworm, and bone marrow disease), deficiency of iron, range of vitamins, folate, copper, and total nutritional deficiencies. Nutritional deficiency anemia is the most common $(2,3)$.

Anemia is associated with a defect in birth outcomes miscarriage, preterm delivery, placental abruption, a low birth weight, a higher risk of prenatal and maternal mortality $(6,7)$. Anemia can reduce physical activities, cognitive capacities, and reduced work productivity (8). Anemia is the most public health concern worldwide affect 27\% (1.93 billion people) of the world's population in 2013. Hence, it is a common public health issue, and particularly in developing countries account for more than $89 \%$ of the burden. According to 2011 WHO estimates anemia affects around 800 million children and women of reproductive age globally $(9,10)$.

The global prevalence of anemia for pregnant women was $38.2 \%$ and for all women of reproductive age was $29.4 \%(5,9)$. In Africa, anemia affects $35 \%$ of women of reproductive age $(9,11)$. Its prevalence is even higher in low-income countries such as Ethiopia due to a lot of contributing factors $(12,13)$. The symptoms of anemia have consistently related the quality of life, a poor-quality diet due to poverty, socioeconomic status, residence, education, and pregnancy status (4). Besides, due to sex-specific experiences, such as pregnancy, bleeding at childbirth, lactation, and menstruation in women of reproductive age (15-49 years) have an increased risk of iron loss and therefore anemia compared to their male counterparts (14).

The illness is diagnosed when hemoglobin levels fall below $12 \mathrm{~g} / \mathrm{dl}$ in adult non-pregnant women and below $11 \mathrm{~g} / \mathrm{dl}$ during pregnancy (1). Based on time there are two main causes of anemia; namely immediate causes and distal causes. The immediate causes are mainly attributable to micronutrient deficiencies (15), physiological adaptations during pregnancy or breastfeeding (16), and infections such as malaria (17), hookworm, and HIV (18). Besides these immediate risk factors of anemia, there are ranges of known distal factors that operate at the household and community levels. These include maternal age (4), education status (13), marital status, occupation (19), rural/urban residence (20), household wealth index $(18,21)$, hormonal contraceptive user, and body mass index $(10,22,23)$. 
Former studies in Ethiopia focused on children, pregnant and lactating women nutrition and associated factors $(12,24,25)$. The previous study also identified factors linked to anemia like residence, wealth status, and modern contraceptive users. However, the majority of these studies are small-scale and are limited to specific localities $(12,21,25-28)$. Even though many of them showed us the wealth index and residence area are significantly associated with anemia (29). These former studies did not explain the urban-rural differentiation on the interaction between anemia and wealth index.

Therefore, this study aims to analyze the urban-rural differential in the association between household wealth index and anemia among women of reproductive age in Ethiopia. The Ethiopian Demographic and Health Surveys (EDHS) is the only source of compressive national data on several characteristics of women of reproductive age (15-49 years). The authors decided to investigate the differentials in anemia among women of reproductive age, using data from the 2016 EDHS.

\section{Method}

\section{Data source, Study design, sample size, and sampling procedures}

This study used data from the 2016 Ethiopian Demographic and Health Survey (EDHS). The EDHS was designed to provide representative data on various health indicators for the whole country across the two city administrations and nine regional states. The survey conducted by the United States Agency for International Development (USAID) in collaboration with the Ministry of Health of Ethiopia and other partner organizations (30).

The 2016 EDHS sample design involved a probabilistic two stages sampling. Each region was stratified into urban and rural areas, yielding 21 sampling strata. Samples of Enumeration Areas (EAs) were selected independently in each stratum in two stages. Implicit stratification and proportional allocation were used at each of the lower administrative levels by sorting the sampling. All women aged 15-49 years who were available in the selected households at the time of the survey were eligible for

participation in the survey. A total of 15,683 women aged 15-49 years were selected for anemia testing in the 2016 EDHS. Among these $92.4 \%(14,489)$ of them were tested for anemia. The final analytic sample for this study included 14,100 participants as depicted in (Fig. 1). 


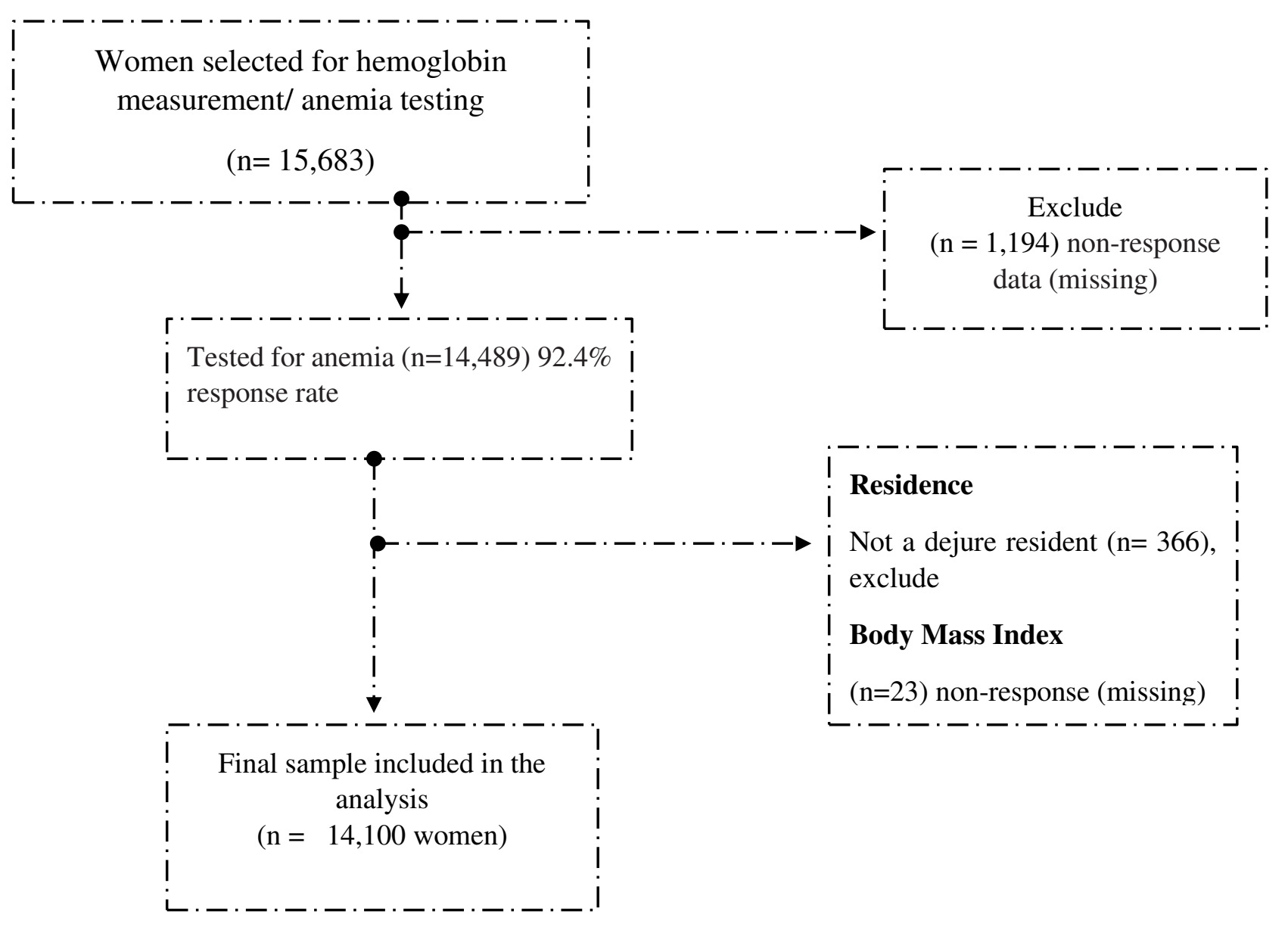

Fig. 1 Schematic presentation of selecting sample from 2016 EDHS data

\section{Variable descriptions}

Anemia was chosen as the main outcome variable for this study. Following WHO recommendations (1), 31), anemia in non-pregnant women was defined as any anemia if their hemoglobin concentration was below $12.0 \mathrm{~g} / \mathrm{dL}$, moderate or severe if it was below $11.0 \mathrm{~g} / \mathrm{dL}$, and severe if it was below $8.0 \mathrm{~g} / \mathrm{dL}$. Anemia in pregnant women was also defined as hemoglobin levels below $11.0 \mathrm{~g} / \mathrm{dL}$ whereas non-pregnant women below $12.0 \mathrm{~g} / \mathrm{dL}$ were considered as anemia $(30,32)$. The main anemia associated variable of interest was the household wealth index and women's place of residence. Based on existing literature, other independent variables included in the analysis are described in Table $1(4,10,18,20,22,23,33)$.

\section{Data analysis}

All the statistical analyses were done taking into account the complex design of the survey. All the estimates were done after weighing the sample by the sample weighing factor and taking into account the cluster design of the study. While it ensures data representativeness at both national and sub-national 
levels, the DHS sampling procedure over-represents small regions. Thus, sample weighting was applied to compensate for the unequal probability of sample selection and ensure the sample resembles the true population distribution. The procedure resulted in a final weighted sample size of 14,100 women (30). Data were analyzed by Chi-square and binary logistic regression models using SPSS software for windows version 20. We described the characteristics of the study population and cross-tabulated our dependent variables with the explanatory variables.

Chi-square was carried out to test the association between the dependent and independent variables. After identifying the association between anemia and independent variables in Chi-square, only one independent variable was included at a time in the regression equation to examine their relationship with anemia. Both the wealth index and place of residence were introduced into the regression equation simultaneously to assess their association with anemia ( $p$-value $<0.2)$. A significant interaction effect would indicate the residence factor on the relationship between household wealth index and the presence of anemia.

Finally, multivariate logistic regression analyses performed to identify the independent associations of explanatory variables with the outcomes of interest, providing Adjusted Odds ratios (AOR) and 95\% confidence intervals (CI). Pearson, Hosmer, and Lemeshow (HL) test to check for model fit (Hosmer \& Lemeshow), and the final model had a better HL chi-square value and p-value. The level of statistical significance set at $5 \%$.

\section{Ethical consideration}

The EDSH survey was implemented by the CSA of Ethiopia. The study protocol and data collection instruments were reviewed for adherence to ethical standards by the Ethiopian Health and Nutrition Research Institute. All study participants asked for informed written consent. Data collectors explained the purpose of the study and that participation in the study was voluntary. Privacy and confidentiality ensured following the ethical requirements of research. The study involved minimal risk for study participants (30). In our study, since this study was a secondary analysis of the Ethiopian Demographic and Health surveys (EDHS) data, which are publicly available, the study did not require any ethics approval. Only DHS program authorization was requested to download the dataset.

\section{Factors associated with Anemia}

\section{Association wealth index and anemia stratified by place of residency}

Variables were included in the bivariate regression analysis based on their association in the chi-squared analyses (Table 3). Bivariate model provides the unadjusted odds ratio of the association between anemia and wealth index with the different explanatory variables. Seven variables were significantly associated 
with anemia in this model. Six variables remained statistically significant in the final multiple regression model controlling with all explanatory variables.

Women of low household wealth index and live in a rural area were more anemic than women of high house wealth index and live in urban. For instance, women who were low household wealth index and rural residence category were 1.37 times more likely to anemic than their counterparts who belong to the rich class and urban residency. Also, in the interactive expression, being a low household health index played a domineering role in the relationship between residency and wealth-index and level of anemia. In the interactive model, the odds ratio of anemia was higher when women are live in rural rather than urban residences (Table 3).

Other predictors of anemia among the studied women were women who were not used hormonal contraceptives, younger age category, no education, and married women (Table 3). The data further show that either using wealth index and women residency jointly or interactively in the regression equation generated the same predictors with differences in their pattern of the odds ratio. The likelihood of anemia was significantly higher among the poor class women living in a rural area in Ethiopia. Having a poor level of household wealth index and not belonging to the urban has a great influence on anemia level.

Table 1. Description of explanatory variables used in the analysis in Ethiopia $2016(n=14,100)$

\begin{tabular}{ll}
\hline Variables & Overall n (wt. \%) \\
\cline { 2 - 2 } Mother's age & $5631(38.4)$ \\
$15-24$ & $4622(34.1)$ \\
$25-34$ & $3847(27.4)$ \\
$35-49$ & \\
Mother's marital Status & $3662(24.9)$ \\
Unmarried & $9024(66.0)$ \\
Married & $1414(9.1)$ \\
Others & \\
Mother's education & $6467(48.7)$ \\
None & $4740(35.2)$ \\
Primary & $2893(16.1)$ \\
Secondary or above & \\
Place of residence & $4563(21.2)$ \\
Urban & $9537(78.8)$ \\
Rural &
\end{tabular}


Poor

Middle

Rich

Body mass index

Under Wt.

Normal

Over Wt.

Hormonal contraceptive use

No

Yes
5487 (35.3)

$1861(19.5)$

6752 (45.2)

3399 (21.2)

9084 (71.1)

1617 (7.7)

$11407(76.8)$

$2693(23.2)$

Abbreviations: Wt.\%: Weighted percent, Wt.: Weight,

Others*: divorced, widowed and no longer living together

Overweight and obese was grouped due to small number of cases

\section{Result}

\section{Socio-demographic characteristics of the sample}

In this study, a total of 14,100 women were including from nine regional states and two city administrations in Ethiopia. The mean age of the women was $28.2 \pm 0.2$ and most anemic women lived in rural areas (25.5\%). Women of low household wealth index categories were anemic (29.6\%) than those rich wealth index categories. women who live in a rural area were (25.5\%) were more anemic than those who live in urban areas (Table 2).

Table 2. Characteristics of the study sample and the status of anemia in women of reproductive age $(\mathrm{n}=14,100)$

\begin{tabular}{|c|c|c|c|}
\hline \multirow[t]{2}{*}{ Variables } & \multicolumn{2}{|l|}{ Anemia } & \multirow[b]{2}{*}{$\mathrm{p}$} \\
\hline & Yes n (Wt. \%) & No n (Wt. \%) & \\
\hline Mother's age & & & 0.020 \\
\hline $15-24$ & $1432(21.9)$ & $4199(78.1)$ & \\
\hline $25-34$ & $1361(25.6)$ & $3261(74.4)$ & \\
\hline $35-49$ & $1054(24.2)$ & $2793(75.8)$ & \\
\hline Mother's marital Status & & & $<0.001$ \\
\hline Unmarried & $746(17.9)$ & $2916(82.1)$ & \\
\hline Married & $2759(26.4)$ & $6265(73.6)$ & \\
\hline Others* & $342(20.8)$ & $1072(79.2)$ & \\
\hline Mother's education & & & $<0.001$ \\
\hline None & 2207 (27.9) & $4260(72.1)$ & \\
\hline Primary & $1111(21.5)$ & $3629(78.5)$ & \\
\hline Secondary or above & $529(16.2)$ & $2364(83.8)$ & \\
\hline Place of residence & & & $<0.001$ \\
\hline Urban & $905(17.1)$ & $3658(82.9)$ & \\
\hline
\end{tabular}




$\begin{array}{clll}\text { Rural } & 2942(25.5) & 6595(74.5) & \\ \text { Employment status } & & & 0.003 \\ \text { Yes } & 1139(21.4) & 3883(78.6) & \\ \text { No } & 2708(24.9) & 6370(75.1) & \\ \text { House hold wealth index } & 2027(29.6) & 3460(70.6) & \\ \text { Poor } & 477(23.8) & 1384(76.2) & \\ \text { Middle } & 1343(19.2) & 5409(80.8) & \\ \text { Rich } & & & 0.035 \\ \text { Under Wt. } & 1096(26.2) & 2303(73.8) & \\ \text { Normal Wt. } & 2404(23.3) & 6680(76.7) & \\ \text { Over Wt. } & 347(21.2) & 1270(78.8) & \\ \text { Body mass index } & & <0.001 \\ \text { No } & 3358(25.3) & 2204(81.2) & \\ \text { Yes } & 489(18.8) & & \end{array}$

Abbreviations: Wt.\%: Weighted percent, Wt.: Weight

Others*: divorced, widowed and no longer living together

P- Value * less than 0.005

\section{Association wealth index and anemia stratified by place of residency}

Variables were included in the bivariate regression analysis based on their association in the chi-squared analyses (Table 3). The bivariate model provides the unadjusted odds ratio of the association between anemia and wealth index with the different explanatory variables. Seven variables were significantly associated with anemia in this model. Six variables remained statistically significant in the final multiple regression model controlling with all explanatory variables.

Women of low household wealth index and live in a rural area were more anemic than women of high house wealth index and live in urban. For instance, women who were low household wealth index and rural residence category were 1.37 times more likely to be anemic than their counterparts who belong to the rich class and urban residency. Also, in the interactive expression, being a low household wealth index played a domineering role in the relationship between residency and wealth-index and level of anemia. In the interactive model, the odds ratio of anemia was higher when women are live in rural rather than urban residence.

Other predictors of anemia among the studied women were women who were not used hormonal contraceptives, younger age category, no education, and married women. The data further show that either using wealth index and women residency jointly or interactively in the regression equation generated the same predictors with differences in their pattern of the odds ratio. The likelihood of anemia 
was significantly higher among the poor class women living in a rural area in Ethiopia. Having a poor level of household wealth index and not belonging to the urban has a great influence on anemia level (Table 3).

Table 3. Association wealth index and anemia stratified by place of residency $(n=14,100)$

\begin{tabular}{|c|c|c|c|c|}
\hline & Rural & & Urban & \\
\hline Variables & Adjusted OR (95\% CI) & $\mathrm{P}$ & Adjusted OR (95\% CI) & $\mathrm{p}$ \\
\hline \multicolumn{5}{|l|}{ Mother's age } \\
\hline $15-24$ & $1.13(1.057-1.68)$ & 0.017 & $0.81(0.59-1.12)$ & 0.199 \\
\hline $24-34$ & $1.27(1.05-1.52)$ & 0.013 & $0.75(0.56-1.01)$ & 0.58 \\
\hline $35-49 *$ & 1 & 1 & & 1 \\
\hline \multicolumn{5}{|l|}{ Mother's education } \\
\hline None & $1.59(1.13-2.23)$ & 0.008 & $0.98(0.68-1.41)$ & 0.906 \\
\hline Primary & $1.27(0.94-1.71)$ & 0.122 & $1.14(0.75-1.730$ & 0.539 \\
\hline Secondary or above* & & 1 & & 1 \\
\hline \multicolumn{5}{|l|}{ Marital status } \\
\hline Unmarried & $0.84(90.62-1.14)$ & 0.268 & $0.81(0.50-1.2)$ & 0.284 \\
\hline Married & $1.53(1.20-1.97)$ & 0.001 & $0.98(0.71-1.35)$ & 0.901 \\
\hline Others* & 1 & 1 & & 1 \\
\hline \multicolumn{5}{|l|}{ Wealth index } \\
\hline Poor & $1.37(1.14-1.65)$ & 0.001 & $0.86(0.46-1.62)$ & 0.648 \\
\hline Middle & $1.11(0.93-1.33)$ & 0.247 & $1.10(0.43-2.77)$ & 0.843 \\
\hline Rich* & 1 & 1 & & 1 \\
\hline \multicolumn{5}{|l|}{ Hormonal contraceptive } \\
\hline yes* & 1 & 1 & & 1 \\
\hline No & $1.67(1.41-1.95)$ & $<0.001$ & $1.53(1.13-2.07)$ & 0.006 \\
\hline \multicolumn{5}{|l|}{ Body mass index } \\
\hline Under weight & $1.06(0.74-1.52)$ & 0.752 & $1.10(0.71-1.7)$ & 0.674 \\
\hline Normal & $0.89(0.65-1.24)$ & 0.507 & $1.10(0.72-1.58)$ & 0.741 \\
\hline Overweight* & 1 & & & \\
\hline \multicolumn{5}{|l|}{ Employment } \\
\hline yes* & 1 & & & \\
\hline No & $1.04(0.89-1.21)$ & 0.634 & $1.159(0.87-1.51)$ & 0.326 \\
\hline
\end{tabular}

Abbreviations: Wt.\%: Weighted percent; OR: Odds Ratio; CI: Confidence Interval *: Reference group

Others: divorced, widowed and no longer living together

\section{Discussion}


This study uses country level, representative data in Ethiopia to describe urban-rural differential in the association between household wealth index and anemia among women in the reproductive age group. This study provides evidence link specific anemia factors related to women's reproductive age group. Since successful anemia prevention strategies should rely on evidence-based approaches, the result of this study should represent recommended public health interventions and policies aimed at a target age group. And then reduce the burden and consequences of anemia in this group.

The prevalence of anemia among women in Ethiopia is $24 \%$ in 2016 (30), making it a moderate public health problem according to the WHO threshold (34). The results suggest that level of household wealth was associated with anemia in women who live in rural. The prevalence of anemia in women varies significantly between urban and rural and region to region in the communities (18). Even though the prevalence of anemia among women age 15-49 declined from 27\% in 2005 to $17 \%$ in 2011, it turns increased to $24 \%$ in 2016 in Ethiopia (30).

In our study, the authors showed that the impact of economic status on the place of residency was the single greatest contributor to anemia among reproductive-age women in Ethiopia. This study found that $29.6 \%$ of women of reproductive age who come from poor house wealth status were anemic. Of the total participants, $25.1 \%$ of anemic women of reproductive age were living in a rural area. The prevalence of anemia $(29.6 \%$ and $25.1 \%$ ) revealed by this study is higher than the national average (24\%). It is also high when compared to urban residency in the country.

In this study, the wealth status of the household was significantly associated with the development of anemia in those who live in rural areas but not in an urban one. Women who had the lowest wealth statuses (AOR=1.37; 95\% CI: 1.14-1.65) increase the chance of developing anemia in rural residency. This finding is consistent with the findings from other studies in low and middle- income countries, which found that the associated factors of anemia among women living in the lowest wealth status were increased when compared with those living in the heights wealth status $(11,18,20,22,23,33)$.

This could be because those from the lowest wealth status in the countryside lack the ability to purchase the quality or quantity of foods compared with those from higher wealth status. Lower-income households purchase less healthful foods compared with higher-income households. It is plausible that diets of women from low wealth status homes, as with urban residents, may have diversified diets and supplements, thereby decreasing their chance of nutrition-related anemia $(32,35,36)$. Another fact also the most reported diet consumption of the household in rural residency is monotonous foodstuff and low diet diversification $(1,32)$. Rural participants with lower socioeconomic status could have greater 
inadequacy of household food resources, food did not last, and they could not afford balanced meals, or reduced meal size or skipped meals $(37,38)$. The women knowledge of different vitamin and mineral containing foods and their benefit may be other contributors (19).

We observed a place of residency -specific variations in the association of anemia among women with similar household wealth status. Place of residency may be mediated anemia difference in similar wealth status in the Ethiopian reproductive women age group. Our study showed associations between the low socioeconomic status of those who live in rural and anemia. This may be in rural regions has been attributed to disparities in health service provision and access, and disease risk, fertility preferences (37, $39,40)$. On the other round, farming can increase the chance of anemia-inducing infectious diseases such as malaria, intestinal parasites like schistosomiasis and hookworm, and such exposures may be more common in rural residency $(33,41)$.

In this study, there were significant differences in anemia between urban and rural areas with similar socioeconomic status. The cause of urban-rural differences was related to the socio-cultural conditions of the participant. The potential cause of this may be restricted access to diverse micronutrient-rich diets (food taboo), not access to mass media, and nutrition information for women who live in rural can exacerbate anemia. Multiple deficiencies tend to cluster within individuals, and the synergistic effect of these deficiencies is important in the development of anemia in rural residency $(39,42,45,46)$. Other than residency and socioeconomic status, women who were not used hormonal contraceptive, younger age category, and no education and married were potential predictors of anemia among the studied participants in Ethiopia; other studies have reported a similar relation (4, 9, 10, 18, 23, 24, 33, 46).

\section{Strengths and limitations}

This study used large population-based data with a large sample size, which is representative of all regions of Ethiopia. Due to the cross-sectional nature of the EDHS data, the cause/effect and the temporal relationship could not be established based on these study findings. Similarly, essential factors such as family size, gravidity, and parity, religion, current breastfeeding, smoking, and HIV factors were not incorporate these variables in the analysis.

\section{Conclusion}

The result of this study should represent recommended public health interventions and policies aiming at a target age group (rural residency) and reduce the burden and consequences of anemia in this age group in the nation. This study provides evidence link specific anemia factors related to women's reproductive age group those who live in the countryside. Since the driver of anemia in this study is a place of residency 
affecting women of reproductive age groups, novel public health interventions should consider urban residency for those women with the lowest household wealth status.

\section{Declaration}

\section{Acknowledgements}

We would like to thank the Demographic and Health Survey (DHS) program for allowing the use of Ethiopian Demographic and Health Survey (EDHS) data for this study.

\section{Author contributions}

Teshager Weldegiorgis Abate, Biruk Getahun, and Mekuriaw Mesfin Birhan are formulating the research question(s), initiate the idea, designing the study and analyzing the data. Teshager Weldegiorgis Abate, Getasew Mulatu Aknaw, Sefealem Assefa Belay, and Dessalegn Demeke are interpreting the results and writing the drafting of the manuscript. Dagninet Derebe Abie, Adela Memberu Alemu, and Yirga Mengiste are writing reviewing and approving the final manuscript. All authors read and approved the final document.

\section{Funding}

The authors have not declared a specific grant for this research from any funding agency in the public, commercial or not-for-profit sectors.

\section{Competing interests}

The author declares that no competing of interest.

\section{Data availibity}

All data generated or analyzed during this study are included in this the manuscript.

\section{Reference}

1. WHO. Haemoglobin concentrations for the diagnosis of anaemia and assessment of severity. Vitamin and Mineral Nutrition Information System. Geneva, World Health Organization, 2011

(WHO/NMH/NHD/MNM/11.1) (http://www.who.int/vmnis/indicators/haemoglobin. pdf, [April 25/2020];

2. Broek N Van Den. Anaemia and micronutrient deficiencies. Br Med Bull. 2003;67:149-60.

3. Nutrition-specific interventions for preventing and controlling anaemia throughout the life cycle: an overview of systematic reviews [Internet]. [cited 2020 Mar 18]. Available from:

https://www.ncbi.nlm.nih.gov/pmc/articles/PMC6513621/

4. Wirth JP, Woodruff BA, Engle-stone R, Namaste SML, Temple VJ, Petry N, et al. Predictors of anemia in women of reproductive age : Biomarkers Reflecting Inflammation and Nutritional Determinants of Anemia ( BRINDA ) project. Am J Clin Nutr. 2017;Jul 1;106:416S-27S.

5. Kassebaum NJ. The Global Burden of Anemia. Hematol Clin NA. 2016;30(2):247-308. 
6. Iron status and its association with pregnancy outcome in Korean pregnant women. - PubMed - NCBI [Internet]. [cited 2020 Mar 19]. Available from: https://www.ncbi.nlm.nih.gov/pubmed/16639418

7. Alene KA, Dohe AM. Prevalence of Anemia and Associated Factors among Pregnant Women in an Urban Area of Eastern Ethiopia. Hindawi. 2014;2014:1-7.

8. Haas JD, Brownlie T. Iron Deficiency and Reduced Work Capacity: A Critical Review of the Research to Determine a Causal Relationship. J Nutr. 2001 Feb 1;131(2):676S-690S.

9. WHO. The Global Prevalence of Anemia in 2011. Geneva; 2015.

10. Gautam S, Min H, Kim H, Id HJ. Determining factors for the prevalence of anemia in women of reproductive age in Nepal : Evidence from recent national survey data. PloS One. 2019;14(6):1-17.

11. Sadeghian M, Fatourechi A, Lesanpezeshki M, Ahmadnezhad E, Ph D. Prevalence of Anemia and Correlated Factors in the Reproductive Age Women in Rural Areas of Tabas. J Fam Reprod Health. 2013;7(3):139-44.

12. Alemayehu A, Gedefaw L, Yemane T, Asres Y. Prevalence, Severity, and Determinant Factors of Anemia among Pregnant Women in South Sudanese Refugees, Pugnido, Western Ethiopia. Anemia [Internet]. 2016 [cited 2020 Mar 18];2016. Available from: https://www.ncbi.nlm.nih.gov/pmc/articles/PMC5183745/

13. Mekonnen FA, Ambaw YA, Neri GT. Socio-economic determinants of anemia in pregnancy in North Shoa Zone , Ethiopia. PloS One. 2018;13(8):1-9.

14. Gautam S, Min H, Kim H, Jeong H-S. Determining factors for the prevalence of anemia in women of reproductive age in Nepal: Evidence from recent national survey data. Kabir R, editor. PLOS ONE. 2019 Jun 12;14(6):e0218288.

15. WHO. Global Nutrition Targets 2025 Anaemia Policy Brief (WHO/NMH/NHD/14.4). Geneva: World Health Organization; 2014.

16. Clara Camaschella. disability during pregnancy. N Engl J Med. 2015;1832-43.

17. WHO. World malaria report 2018. Geneva: World Health Organization; 2018. Licence: CC BY-NC-SA 3.0 IGO;

18. Kibret KT, Chojenta C, Arcy ED, Loxton D. Spatial distribution and determinant factors of anaemia among women of reproductive age in Ethiopia : a multilevel and spatial analysis. BMJ Open. 2019;9(Apr 1;9(4):e027276):1-14.

19. Hossain M, Islam Z, Sultana S, Rahman AS, Hotz C, Haque A, et al. nutrients E ff ectiveness of Workplace Nutrition Programs on Anemia Status among Female Readymade Garment Workers in Bangladesh : A Program Evaluation. Nutrients. 2019;11:1-23.

20. Petry N, Olofin I, Hurrell RF, Boy E, Wirth JP, Moursi M, et al. The Proportion of Anemia Associated with Iron Deficiency in Low , Medium, and High Human Development Index Countries : A Systematic Analysis of National Surveys. Nutrients. 2016;Nov;8(11):693.

21. Addis Alene K, Mohamed Dohe A. Prevalence of Anemia and Associated Factors among Pregnant Women in an Urban Area of Eastern Ethiopia [Internet]. Vol. 2014, Anemia. Hindawi; 2014 [cited 2020 Mar 19]. p. e561567. Available from: https://www.hindawi.com/journals/anemia/2014/561567/ 
22. Ii N, Saseendran K, Andrew P, Channon A, Knight G, Madise NJ. A multilevel approach to correlates of anaemia in women in the Democratic Republic of Congo : fi ndings from a nationally representative survey. Eur J Clin Nutr. 2019;Nov 4:1-12.

23. Hakizimana D, Nisingizwe MP, Logan J, Wong R. Identifying risk factors of anemia among women of reproductive age in Rwanda - a cross-sectional study using secondary data from the Rwanda demographic and health survey 2014 / 2015. BMC Public Health. 2019;Dec 1 19(1):1-11.

24. Alem M, Enawgaw B, Gelaw A, Kenaw T, Seid M, Olkeba Y. Prevalence of Anemia and Associated Risk Factors among Pregnant Women Attending Antenatal Care in Azezo Health Center Gondar Town, Northwest Ethiopia. J Interdiscip Histopathol. 2013 Jun 1;1:1.

25. Kawo KN, Asfaw ZG, Yohannes N. Multilevel Analysis of Determinants of Anemia Prevalence among Children Aged 6-59 Months in Ethiopia: Classical and Bayesian Approaches [Internet]. Vol. 2018, Anemia. Hindawi; 2018 [cited 2020 Mar 19]. p. e3087354. Available from: https://www.hindawi.com/journals/anemia/2018/3087354/

26. Melku M, Addis Z, Alem M, Enawgaw B. Prevalence and Predictors of Maternal Anemia during Pregnancy in Gondar, Northwest Ethiopia: An Institutional Based Cross-Sectional Study [Internet]. Vol. 2014, Anemia. Hindawi; 2014 [cited 2020 Mar 19]. p. e108593. Available from: https://www.hindawi.com/journals/anemia/2014/108593/

27. Kefiyalew F, Zemene E, Asres Y, Gedefaw L. Anemia among pregnant women in Southeast Ethiopia: prevalence, severity and associated risk factors. BMC Res Notes. 2014 Nov 3;7(1):771.

28. Prevalence of anemia and associated factors among pregnant women in Southern Ethiopia: A community based cross-sectional study [Internet]. [cited 2020 Mar 19]. Available from:

https://www.ncbi.nlm.nih.gov/pmc/articles/PMC5724831/

29. Tesfaye TS, Tessema F, Jarso H. Prevalence of Anemia and Associated Factors Among Apparently Healthy; Urban and Rural Residents in Ethiopia: A Comparative Cross-Sectional Study. Vol. 11, https://www.dovepress.com/. Dove Press; 2020. p. 89-96.

30. CentralStatisticalAgency(CSA)[Ethiopia]andICF.2016. Ethiopian Demographic and Health servey 2016. Addis Ababa, Ethiopia, and Rockville, Maryland, USA: CSA and ICF.; 2017.

31. WHOReproductiveHealthLibrary. WHO recommendation on the method for diagnosing anaemia in pregnancy (December 2016). The WHO Reproductive Health Library; Geneva: World Health Organization. Source; 2018.

32. Balarajan Y, Ramakrishnan U, Özaltin E, Shankar AH, Subramanian S V. Anaemia in low-income and middle-income countries. The Lancet. 2011;378(9809):2123-35.

33. Asres Y, Yemane T, Gedefaw L. Determinant Factors of Anemia among Nonpregnant Women of Childbearing Age in Southwest Ethiopia : A Community Based Study. Internatinal Sch Res Not. 2014;2014:1-8.

34. Benoist B de, McLean E, Egli I, Cogswell M. Worldwide prevalence of anaemia 1993-2005: WHO Global Database on Anemia, WHO, ed. Geneva: WHO; 2008.

35. French SA, Tangney CC, Crane MM, Wang Y, Appelhans BM. Nutrition quality of food purchases varies by household income : the SHoPPER study. BMC Public Health. 2019;19(1):231. 
36. Pechey R, Monsivais P. Socioeconomic inequalities in the healthiness of food choices : Exploring the contributions of food expenditures. Prev Med. 2016;88:203-9.

37. Dean WR, SharkeyJR. Rural and Urban Differences in the Associations between Characteristics of the Community Food Environment and Fruit and Vegetable Intake. J Nutr Educ Behav. 2011;43(6):426-33.

38. Desta M, Akibu M, Tadese M, Tesfaye M. Dietary Diversity and Associated Factors among Pregnant Women Attending Antenatal Clinic in Shashemane, Oromia, Central Ethiopia : A Cross-Sectional Study. J Nutr Metab. 2019;2019:7-10.

39. Gebre E, Worku A, Bukola F. Inequities in maternal health services utilization in Ethiopia 2000 - 2016 : magnitude , trends , and determinants. Reprodactive Health. 2018;15(1):119.

40. Bobo FT, Yesuf EA, Woldie M. Inequities in utilization of reproductive and maternal health services in Ethiopia. Int J Equity Health. 2017;16(1):105.

41. Berhe K, Fseha B, Gebremariam G, Teame H, Etsay N, Welu G, et al. Risk factors of anemia among pregnant women attending antenatal care in health facilities of Eastern Zone of Tigray, Ethiopia, casecontrol study, 2017/18. Pan Afr Med J. 2019;34(121):1-10.

42. Kenea D, Jisha H. Urban - rural disparity and determinants of delivery care utilization in Oromia region, Ethiopia : Community - based cross - sectional study. Int J Nurs Pract. 2017;23(1):1-10.

43. Keflie TS, Samuel A, Lambert C, Nohr D, Biesalski HK. Dietary Patterns and Risk of Micronutrient Deficiencies : their Implication for Nutritional Intervention in Ethiopia. J Nutr Health Food Sci. 2013;6(1):1-16.

44. Getnet W, Aycheh W, Tessema T. Determinants of Food Taboos in the Pregnant Women of the Awabel District , East Gojjam Zone, Amhara Regional State in Ethiopia. Av Puplic Health. 2018;2018.

45. Little M, Zivot C, Humphries S, Dodd W, Patel K, Dewey C. Burden and Determinants of Anemia in a Rural Population in South India: A Cross-Sectional Study. Anemia. 2018;2018.

46. Prakash S, Yadal K. Incidence of Anemia and its Socio-demographic Determinants among Pregnant Women Attending for antenatal care: A cross sectional study. Int J Med Health Res. 2015;1(3):12-7. 
Figures

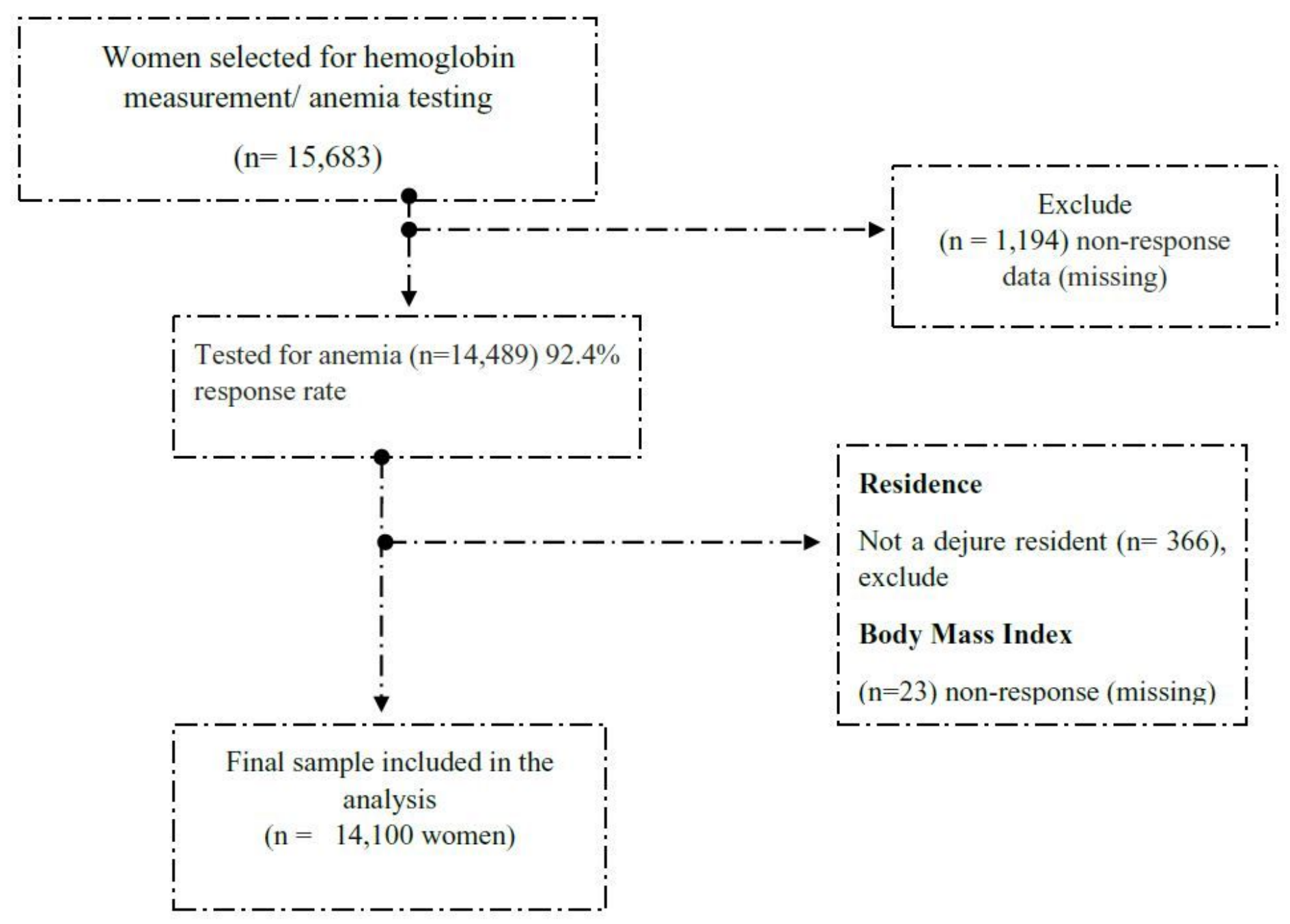

\section{Figure 1}

Schematic presentation of selecting sample from 2016 EDHS data 